ANDRIOLO, J.L.; DUARTE, T.S.; LUDKE, L.; SKREBSKY, E.C. Caracterização e avaliação de substratos para o cultivo do tomateiro fora do solo. Horticultura Brasileira, Brasília, v. 17, n. 3, p. 215-219, novembro 1999.

\title{
Caracterização e avaliação de substratos para o cultivo do tomateiro fora do solo.
}

\author{
Jerônimo L. Andriolo; Tatiana S. Duarte; Loeni Ludke; Etiane C. Skrebsky \\ UFSM-CCR-Depto. de Fitotecnia, 97.119-900, Santa Maria-RS.
}

\begin{abstract}
RESUMO
Três diferentes materiais foram avaliados quanto ao seu potencial de uso como substrato para o cultivo do tomateiro. Os experimentos foram realizados no Departamento de Fitotecnia da UFSM, em Santa Maria-RS e os materiais avaliados foram: húmus proveniente da minhocultura, casca de arroz e substrato comercial (Plantmax Folhosas). O substrato comercial foi comparado no seu estado original correspondente a primeira utilização e também na sua segunda utilização com a mesma cultura. A casca de arroz foi comparada no seu estado puro e também em mistura com solo da região na proporção de $50 \%$ de cada componente. A caracterização física foi efetuada pela determinação da densidade e da massa úmida e pelo cálculo do volume retido e da capacidade máxima de retenção de água. A avaliação qualitativa dos substratos foi realizada por meio de avaliações do crescimento e produção de frutos de dois cultivos de tomateiro, respectivamente no outono-inverno e primavera-verão do ano de 1997. O húmus apresentou características físicas similares ao substrato comercial, enquanto que a casca de arroz reteve volume de água aproximadamente $50 \%$ inferior aos outros dois substratos avaliados. Porém, essa diferença diminuiu quando a casca de arroz foi misturada com o solo. O crescimento das plantas na casca de arroz foi inferior e a produção de frutos atingiu apenas $56 \%$ daquela obtida nos outros substratos. Tanto a mistura de casca de arroz e solo como os outros substratos avaliados se mostraram apropriados para o cultivo do tomateiro fora do solo.
\end{abstract}

Palavras-chave: Lycopersicon esculentum, crescimento, rendimento, fertirrigação.

\begin{abstract}
Evaluation of substrates for growing tomatoes in soilless culture.

Three different organic materials were tested at the UFSM, Santa Maria, Brazil, as substrate for growing tomatoes in soilless culture. Humus originated from the digestion of organic materials by earthworms, rice husk, and a commercial substrate "Plantmax Folhosas" were used. Two successive cycles of tomato plants were evaluated, by replacing old plants with young ones after the first cycle of the crop. Rice husk was compared solely in a homogeneous form and as a mixture with soil in a $50 \%$ basis. Substrates were characterized by physical parameters of bulk density, wetness and through calculation of the volumetric water content and maximum capacity of water retention. Quality of substrates was evaluated by measuring growth and yield of two successive tomato crops, in the Autumn and the Spring of 1997. Comparisons between humus and the commercial substrate showed similar physical characteristics, while volumetric water content of rice husk was about $50 \%$ lower. This difference was reduced when soil was added to the rice husk. Growth of tomato plants on rice husk was lower and fruit yield achieved a maximum value of $56 \%$ of that observed on the two other substrates. Humus, the commercial substrate "Plantmax Folhosas" and the mixture of rice husk with soil may be used successfully for growing tomatoes in soilless culture.
\end{abstract}

Keywords: Lycopersicon esculentum, yield, fertigation, growth.

(Aceito para publicação em 16 de agosto de 1999)

$\mathrm{O}$ cultivo de hortaliças utilizando substratos como suporte das raízes é uma técnica amplamente empregada na maioria dos países de horticultura avançada (Musard \& Letard, 1990; Alarcon et al., 1997; Rosa et al., 1997). Essa modalidade de cultivo representa grande avanço frente aos sistemas de cultivo no solo, porque oferece como principais vantagens: 1) o manejo mais adequado da água, evitando a umidade excessiva em torno das raízes, que é muito comum no solo em períodos de elevada precipitação pluviométrica; 2) o fornecimento dos nutrientes em doses e épocas apropriadas, de acordo com os períodos de maior necessidade ao longo do ciclo de produção das culturas; 3 ) a redução dos riscos de salinização do meio radicular, por meio de drenagem de nutrientes excedentes e não absorvidas pelas plantas; 4) a possibilidade de diminuir a ocorrência de problemas de ordem fitossanitária das culturas, tanto da parte aérea como das raízes (Blanc, 1987; FAO, 1990b). Os benefícios diretos dessa técnica se traduzem principalmente em maior rendimento e melhor qualidade dos produtos colhidos, associados a menor utilização de defensivos agrícolas. Como benefício indireto, pode-se citar um menor risco de perda das lavouras, permitindo melhor planejamento da produção e contribuindo para a profissionalização dos produtores frente a um mercado cada vez mais competitivo. 
Um substrato agrícola é definido como todo material, natural ou artificial, colocado em um recipiente, puro ou em mistura, que permita a fixação do sistema radicular e sirva de suporte a planta (Blanc, 1987). Do ponto de vista do crescimento e da atividade radicular, um substrato deve armazenar um determinado volume de água e ao mesmo tempo manter teor adequado de oxigênio em torno das raízes. O oxigênio é indispensável para a respiração das raízes a fim de suprir a energia necessária à absorção dos nutrientes (Salsac et al., 1987). Um substrato que guarda uma proporção correta entre as fases sólida e líquida favorece, portanto, a atividade fisiológica das raízes e ao mesmo tempo evita as condições favoráveis ao aparecimento de moléstias radiculares, especialmente as podridões fúngicas $\mathrm{e}$ bacterianas. Qualquer material, orgânico ou mineral, que preencha estas condições, sem ser fitotóxico, apresenta potencial de uso como substrato agrícola.

O desenvolvimento da cultura do tomateiro em substratos, nas diferentes regiões do Brasil, depende de duas condições fundamentais: 1) da disponibilidade de fertilizantes solúveis e com preços compatíveis para efetuar a fertirrigação e 2) da disponibilidade de matérias-primas abundantes e baratas com potencial de utilização como substratos para as culturas. A primeira condição já foi atingida no País, uma vez que formulações e doses utilizadas em países do Hemisfério Norte já foram adaptadas aos fertilizantes e equipamentos existentes no mercado nacional (Andriolo et al., 1997; Andriolo \& Poerschke, 1997). A segunda condição depende ainda de estudos com a finalidade de inventariar os materiais disponíveis nas diferentes regiões e caracterizar o seu potencial de uso como substrato agrícola.

Este trabalho foi realizado em duas etapas, tendo como objetivo na primeira fase a caracterização das principais propriedades físicas de alguns materiais disponíveis no Estado do Rio Grande do Sul com potencial de utilização como substratos para a cultura do tomateiro. $\mathrm{Na}$ segunda fase foi feita a avaliação do crescimento e da produção de frutos das plantas cultivadas nos diferentes materiais selecionados e caracterizados.

\section{MATERIAL E MÉTODOS}

Os experimentos foram conduzidos no Departamento de Fitotecnia da Universidade Federal de Santa Maria-RS, (latitude: 2943'S, longitude: 534' $\mathrm{W}$, altitude: $95 \mathrm{~m}$ ), no ano de 1997 . Os materiais comparados foram a casca de arroz, o húmus proveniente de resíduos do rúmen de bovinos abatidos na indústria frigorífica obtidos por meio da digestão por minhocas e um substrato comercial definido pelo fabricante como sendo uma mistura de matéria orgânica de origem vegetal e vermiculita expandida (Plantmax Folhosas). A casca de arroz foi submetida a queima parcial antes de ser utilizada. O húmus foi empregado sem qualquer modificação. $\mathrm{O}$ substrato comercial foi dividido em dois lotes: comercial de primeira utilização (comercial-1) e de segunda utilização (comercial-2), esse último reutilizado após ter sido utilizado no cultivo do tomateiro. O comportamento do tomateiro em cada um dos materiais foi avaliado por meio de dois cultivos sucessivos, sendo o primeiro no período entre fevereiro e julho e o segundo entre agosto e dezembro de 1997. Para implantar o segundo ciclo da cultura, removeu-se dos diferentes substratos a raiz principal das plantas da cultura anterior, transplantando-se novamente mudas de tomateiro no estádio de seis folhas. Não houve manipulação dos substratos de um ciclo para outro, tendo sido retiradas ao acaso cinco sacolas de cada material para efetuar a caracterização física dos substratos antes de iniciar o segundo cultivo. Após concluída a caracterização, as sacolas foram identificadas e recolocadas nas suas respectivas posições dentro do ensaio.As plantas que cresceram nas sacolas amostradas não foram utilizadas para efetuar medidas. Tendo em vista os baixos resultados obtidos com a casca de arroz na primeira cultura, esse material foi inteiramente substituído por uma mistura de casca de arroz e solo da estufa (Podzólico vermelho-amarelo, Unidade de Mapeamento São Pedro), na proporção de $50 \%$ de cada componente, antes de iniciar o segundo ciclo da cultura.

\section{riais}

a. Caracterização física dos mate-

As variáveis físicas determinadas para cada substrato foram a densidade e a capacidade máxima de retenção de água. Para realizar essas determinações, os materiais foram previamente secos em estufa, na temperatura de aproximadamente $50^{\circ} \mathrm{C}$, durante 48 horas. Para determinar a densidade de cada substrato, mediu-se a massa seca correspondente ao volume de um litro, após adensamento natural por agitação manual. Imediatamente após a pesagem, os materiais foram acondicionados em sacolas plásticas com capacidade de dois litros e saturados com água. Após a saturação, as sacolas foram fechadas na parte superior e grande número de perfurações finas foi efetuado na parte inferior e lateral das mesmas, com auxílio de uma agulha histológica. Para assegurar a livre drenagem da água excedente através dos orifícios, as sacolas foram suspensas durante aproximadamente 14 horas, no período entre o final da tarde e o início da manhã seguinte, quando foram novamente pesadas para determinar a massa úmida. A diferença de massa entre os valores das pesagens úmida e seca representou o volume de água retido e esse valor expresso em porcentagem da massa úmida, representou a capacidade máxima de retenção de água (Gras, 1987; Andriolo \& Poerschke, 1997Foram efetuadas cinco repetições para cada uma das determinações e no final foram calculadas as médias.

Para avaliar a evolução das características físicas dos substratos, as determinações foram repetidas no início de cada uma das duas culturas de tomateiro, respectivamente em março (ciclo 97/ 1) e julho (ciclo 97/2) de 1997, e também uma avaliação final após encerramento do último ensaio (98/1). Para realizar essas determinações, foi sorteada uma sacola dentro da área útil de cada parcela, mais uma adicional entre as quatro parcelas de cada bloco, totalizando cinco amostras de cada material. Em cada ciclo, as medidas foram efetuadas sempre sobre o material das mesmas sacolas, de forma a detectar sua evolução no decorrer dos ciclos de cultura.

b. Avaliação do crescimento e desenvolvimento da cultura

Para avaliar o comportamento do tomateiro (Lycopersicon esculentum Mill.) nos diferentes materiais estudados, foram implantadas duas culturas. A primeira com o híbrido longa-vida Diva, semeado em 20 de fevereiro etransplantado para as sacolas no dia 19 de março. 
O experimento foi concluído aos 138 dias após o transplante, quando foi determinada a massa seca (após secagem em estufa a $\pm 50^{\circ} \mathrm{C}$, até peso constante) de folhas, caule e frutos e a área foliar, esta última por meio da relação entre a massa seca e a área de 40 discos (diâmetro de oito milímetros) de cada planta, coletados em folhas representativas do dossel da cultura. A segunda cultura foi realizada com o híbrido Monte Carlo, com semeadura em 22 de agosto e transplante em 21 de setembro. $\mathrm{O}$ experimento foi concluído aos 87 dias após o transplante, determinando-se as mesmas variáveis de crescimento definidas no ensaio anterior. As mudas destinadas à implantação de ambas as culturas foram produzidas em bandejas de poliestireno e transplantadas no estádio de seis folhas definitivas. As sacolas plásticas de coloração branca e capacidade para 10 litros foram preenchidas com os seguintes volumes, em litros, de cada um dos substratos secos: húmus $=3,9$; comercial- $1=3,7$; comercial- $2=4,1$; casca de arroz $=8,5$; casca de arroz e solo $=$ 5,7 . O volume de cada um dos substratos foi determinado de acordo com a capacidade de retenção de água de cada material, a fim de manter para cada planta um volume semelhante de água facilmente utilizável, da ordem de $1.250 \mathrm{~mL}$ planta1 . As sacolas contendo os substratos foram arranjadas sobre camalhões de aproximadamente $25 \mathrm{~cm}$ de altura, revestidos com filme de polietileno opaco de coloração preta, construídos no interior de uma estufa de polietileno tipo "Pampeana" de $500 \mathrm{~m}^{2}$, localizada no Departamento de Fitotecnia da Universidade Federal de Santa Maria-RS. O delineamento experimental foi o de blocos casualizados completos, com quatro repetições, sendo a área útil de cada parcela formada por cinco sacolas, que posteriormente receberam as mudas.

A fertirrigação foi efetuada em intervalos semanais durante todo o ciclo das culturas, com as seguintes quantidades de fertilizantes, em $g$ planta ${ }^{-1}$ : nitrato de potássio $=4$; nitrato de cálcio $=6,3$; super fosfato simples $=1,5$; sulfato de magnésio $=3$. O ferrro foi fornecido separadamente através de uma formulação quelatizada, na dose de $0,13 \mathrm{~mL}_{\text {planta }}{ }^{-1}$ e os demais micronutrientes através de uma solução completa, na dose de $0,7 \mathrm{~mL}$ planta $^{-1}$ (Andriolo \& Poerschke,1997). Nos intervalos entre duas fertirrigações sucessivas, foi efetuada somente a irrigação das plantas, por gotejamento. A frequência e os volumes de água fornecidos em cada irrigação foram estimados de forma a repor o consumo pela transpiração das plantas e ao mesmo tempo restabelecer o volume retido na capacidade máxima de retenção de cada substrato. Uma drenagem de aproximadamente $30 \%$ do volume retido foi efetuada no dia anterior a cada uma das fertirrigações, a fim de lixiviar para fora das sacolas os elementos eventualmente não absorvidos pelas plantas. $\mathrm{O}$ manejo do ambiente da estufa foi efetuado por ventilação natural, por meio da abertura das cortinas laterais às 9:00h e fechamento às 15:00h, aproximadamente. A densidade de plantas foi de 2,2 plantas $\mathrm{m}^{2}$, em fileiras simples $(1,0 \mathrm{~m}$ entre fileiras e $0,45 \mathrm{~m}$ entre plantas), conduzidas com uma haste por meio de fitas plásticas, removendo-se as ramificações axilares uma vez por semana. Um hormônio vegetal comercial (citocinina na concentração $8^{\prime} 10^{-5} \%$ ) foi aplicado duas vezes por semana durante o período de inverno, quando as temperaturas diurnas se situaram em valores inferiores a $18^{\circ} \mathrm{C}$, a fim de estimular o crescimento dos frutos jovens e compensar possíveis falhas na polinização (FAO, 1990a). Na primeira cultura foram efetuadas duas aplicações de fungicidas para o controle do oídio e na segunda cul-

Tabela 1 - Valores de densidade, massa úmida, volume retido e capacidade máxima de retenção de água (CR) dos substratos, no início dos dois ciclos e no final do segundo ciclo da cultura do tomateiro. Santa Maria, UFSM, 1997*. (Os dados entre parênteses indicam os valores relativos em relação àqueles medidos no ciclo 97/1).

\begin{tabular}{|c|c|c|c|c|}
\hline Substrato & $\begin{array}{c}\text { Densidade } \\
\left(\mathrm{g} \mathrm{L}^{-1}\right)\end{array}$ & $\begin{array}{c}\text { Massa úmida } \\
\left(\mathrm{g} \mathrm{L}^{-1}\right)\end{array}$ & $\begin{array}{c}\text { Volume retido } \\
\left(\mathrm{ml} \mathrm{L}^{-1}\right)\end{array}$ & $\begin{array}{l}\text { CR } \\
(\%)\end{array}$ \\
\hline \multicolumn{5}{|c|}{ Início do ciclo da cultura 97/1 } \\
\hline Húmus & 483,9 a & $1.126,0 \mathrm{a}$ & 642,1 a & 57 \\
\hline Comercial-1 & $345,8 \mathrm{~b}$ & $1.018,5 \mathrm{a}$ & 672,7 a & 66 \\
\hline Comercial-2 & $312,7 \mathrm{c}$ & $920,0 \mathrm{~b}$ & $607,3 \mathrm{~b}$ & 66 \\
\hline Casca de arroz & $140,9 d$ & $434,7 \mathrm{c}$ & $293,8 \mathrm{C}$ & 66 \\
\hline \multicolumn{5}{|c|}{ Início do ciclo da cultura 97/2 } \\
\hline Húmus & 448,4 b $(92,6)$ & $1.202,0 \mathrm{a}(106)$ & 753,6 a (117) & 63 \\
\hline Comercial-1 & 326,2 c $(94,3)$ & 916,1 c (90) & 589,9 b (88) & 64 \\
\hline Comercial-2 & $283,1 \mathrm{~d}(90,5)$ & $810,8 \mathrm{~d}(88)$ & 527,7 c (87) & 65 \\
\hline Casca de arroz e solo & 677,9 a & $1.112,4 \mathrm{~b}$ & $434,5 d$ & 39 \\
\hline \multicolumn{5}{|c|}{ Final do ciclo da cultura $97 / 2$} \\
\hline Húmus & 391,5 b $(80,9)$ & $1.079,3$ a (96) & 687,8 a (107) & 64 \\
\hline Comercial-1 & 273,6 c $(79,1)$ & 899,8 b (88) & 626,2 b (93) & 70 \\
\hline Comercial-2 & $244,4 d(78,1)$ & 813,9 c (88) & 569,5 c (94) & 70 \\
\hline Casca de arroz e solo & 678,4 a $(100)$ & $1.088,8$ a (98) & 410,4 d (94) & 38 \\
\hline
\end{tabular}

* Médias seguidas pela mesma letra na vertical não diferem entre si pelo teste de Duncan a $5 \%$ de probabilidade. 
tura somente duas aplicações de acaricida foram necessárias.

\section{RESULTADOS E DISCUSSÃO} riais

a. Caracterização física dos mate-

O húmus foi o material que apresentou a maior densidade, seguido pela substrato comercial e pela casca de arroz (Tabela 1). A adição de solo à casca de arroz aumentou a densidade de 141 para $678 \mathrm{~g} \mathrm{~L}^{-1}$. O húmus e o substrato comercial apresentaram perda de densidade de um ciclo de cultura para o outro. A perda foi visível já no final do primeiro ciclo, variando de 8 a $10 \%$, aproximadamente. $\mathrm{O}$ substrato comercial-2, constituído pelo mesmo material do comercial-1 e tendo passado por um ciclo de cultura adicional, apresentou redução mais acentuada após o cultivo 97/1. No final do ciclo 97/2, os três substratos acumularam uma perda semelhante, da ordem de $20 \%$, em relação aos valores iniciais. Essa perda não foi observada na mistura de casca de arroz e solo, que mostrou densidade similar após um ciclo de cultura.

O húmus e o comercial-1 foram os materiais que apresentaram valores iniciais mais elevados de massa úmida, seguidos pelos substratos comercial-2 e a mistura de casca de arroz e solo (Tabela 1). Essa variável mostrou tendência decrescente entre o início do primeiro e o final do segundo ciclo de produ- ção e de forma mais intensa no substrato comercial. A diferença entre a massa úmida e a densidade indica o volume de água retido por unidade de volume de substrato. No início do ciclo 97/1, o maior volume foi medido no húmus $\mathrm{e}$ no substrato comercial-1, enquanto a casca de arroz isolada reteve aproximadamente $50 \%$ do volume retido pelos outros substratos estudados. Os valores do volume retido mostraram alteração após um ciclo de cultura, passando o húmus a reter maior volume que os demais substratos, até o final do experimento. A mistura de casca de arroz e solo também mostrou redução do volume de água retido após um ciclo de cultura e seu valor absoluto foi aproximadamente $40 \%$ menor do que aquele do húmus. Os valores de capacidade máxima de retenção de água variaram aproximadamente entre 60 e $70 \%$ tanto para o húmus como para o substrato comercial e foram próximos de $40 \%$ para a mistura de casca de arroz e solo.

A vida útil de um substrato orgânico é determinada principalmente pela velocidade das reações de decomposição, que modificam a textura do material e, consequentemente, a proporção entre as fases sólida, líquida e gasosa. Tanto o húmus como o substrato comercial mostraram degradação, estimada pela perda de densidade, após dois ciclos de cultura. Entretanto, esta degradação repercutiu de maneira diferente sobre o volume retido por esses dois materiais, que diminuiu apenas no substrato comercial. Esse comportamento está provavelmente relacionado com a composição física desses dois substratos. O húmus se caracteriza por maior homogeneidade de partículas e sua degradação é mais lenta, pois o material já passou por transformações biológicas no aparelho digestivo das minhocas. Por outro lado, o substrato comercial empregado no experimento foi definido pelo fabricante como uma mistura de vermiculita e resíduos vegetais triturados, o que implica maior heterogeneidade de partículas. A vermiculita é um material constituído por lamelas expandidas de silicatos, que sofrem rapidamente fragmentação mecânica e saturação química. A fração fina das partículas desagregadas é facilmente carregada pelos volumes drenados. Esses fatores reduzem a plasticidade, aumentando a compactação e diminuindo o volume de água retido (Moinereau et al., 1987).

A massa úmida dos substratos comparados não se constituiu em fator limitante à sua utilização. Essa variável se torna limitante somente quando atinge valores muito elevados, dificultando o seu manuseio na lavoura. Cada sacola contendo aproximadamente quatro litros de húmus, que foi o substrato que apresentou o maior valor para essa variável, atingiu uma massa úmida inferior a cinco quilogramas. Por outro lado, o volume de água retido foi muito baixo na

Tabela 2 - Valores de matéria seca de caule, folhas, frutos e total da planta, fração da matéria seca total alocada para os frutos (FMSF), índice de área foliar (IAF) e produção de frutos de tomateiro determinados ao término de cada um dos experimentos. Santa Maria, UFSM, 1997*.

\begin{tabular}{|c|c|c|c|c|c|c|c|}
\hline \multirow{2}{*}{ Substrato } & \multicolumn{4}{|c|}{ Matéria seca (g planta-1) } & \multirow{2}{*}{ FMSF } & \multirow{2}{*}{ IAF } & \multirow{2}{*}{$\begin{array}{l}\text { Produção } \\
\text { de frutos } \\
\text { (g planta-1) }\end{array}$} \\
\hline & Caule & Folhas & Frutos & Total & & & \\
\hline \multicolumn{8}{|l|}{ Ciclo da cultura 97/1 } \\
\hline Húmus & $67,3 \mathrm{~b}$ & 51,3 a & 135,4 a & $254,2 a b$ & 0,53 & $4,7 a b$ & $2.709 \quad a$ \\
\hline Comercial-1 & $96,1 \mathrm{ab}$ & $61,0 \mathrm{a}$ & $108,2 a b$ & $265,3 a b$ & 0,41 & $6,0 \mathrm{a}$ & $2.164 \mathrm{ab}$ \\
\hline Comercial-2 & 101,7 a & 56,3 a & 128,1 a & 286,1 a & 0,45 & $5,1 a b$ & $2.562 \quad a$ \\
\hline Casca de arroz & $83,6 \mathrm{~b}$ & $33,5 \mathrm{a}$ & 77,2 b & $194,4 \quad b$ & 0,40 & 3,0 & $1.544 \quad b$ \\
\hline \multicolumn{8}{|l|}{ Ciclo da cultura $97 / 2$} \\
\hline Húmus & $87,1 \mathrm{ab}$ & $60,7 \mathrm{a}$ & 120,1 a & 267,8 a & 0,44 & $3,4 \quad b$ & $2.401,7 \mathrm{a}$ \\
\hline Comercial-1 & $95,4 \mathrm{a}$ & $68,5 \mathrm{a}$ & 137,9 a & 301,8 a & 0,45 & $4,7 \mathrm{a}$ & $2.757,9 \mathrm{a}$ \\
\hline Comercial-2 & $86,3 a b$ & 56,3 a & 105,9 a & 260,5 a & 0,43 & $3,1 \quad b$ & $2.117,4 \mathrm{a}$ \\
\hline Casca de arroz e solo & $81,7 \quad b$ & $61,1 \mathrm{a}$ & 141,1 a & 283,9 a & 0,50 & $3,3 \mathrm{~b}$ & $2.823,0 \mathrm{a}$ \\
\hline
\end{tabular}

* Médias seguidas pela mesma letra não diferem entre si pelo teste de Duncan a 5\% de probabilidade. 
casca de arroz empregada isoladamente. Nesse substrato, a água disponível às plantas diminuiu muito rapidamente, exigindo irrigações frequentes. Esse inconveniente se torna ainda mais acentuado quando a demanda evaporativa da atmosfera é elevada. Trata-se de uma situação pouco favorável à cultura, porque dificulta o manejo correto da água e aumenta os volumes drenados, que estão associados também a uma maior perda de nutrientes. A mistura desse material com o solo se mostra uma alternativa simples e eficiente para minimizar seus defeitos e permitir o emprego como substrato.

\section{b. Comportamento da cultura do} tomateiro

A produção de matéria seca no final dos ensaios mostra que a repartição da biomassa total entre os órgãos da parte aérea da planta foi diferente entre os substratos estudados (Tabela 2). No ciclo 97/1, a produção de matéria seca vegetativa, formada pelo caule e folhas, foi mais elevada nos substratos comercial-1 e comercial-2. O húmus e a casca de arroz apresentaram valores semelhantes para essa variável. Porém, a maior diferença foi constatada na produção de frutos, que foi $38 \%$ menor na casca de arroz quando comparada com a média dos outros três substratos, que não diferiram significativamente entre si. A fração de matéria seca alocada para os frutos foi mais elevada no húmus e no comercial-2. A mistura de casca de arroz e solo mostrou o valor mais baixo do índice de área foliar.

No ciclo 97/2, não houve diferenças significativas entre os substratos na produção de matéria seca de folhas e de frutos (Tabela 2). Porém, houve diferença na acumulação de matéria seca do caule, que foi mais baixa na mistura de casca de arroz e solo em relação ao substrato comercial-1. A produção de frutos não mostrou diferenças significativas entre os tratamentos, porém o valor mais elevado foi observado na mistura de casca de arroz e solo.

A utilização da casca de arroz isoladamente reduziu a produção de frutos, indicando que para ser eficiente como substrato esse material deverá ser empregado em mistura com outros materiais capazes de reter um maior volume de água. $\mathrm{O}$ baixo volume retido repercute negativamente sobre o rendimento da cultura porque dificulta o manejo tanto da água como dos nutrientes. Com relação ao primeiro, o volume disponível às plantas passa rapidamente de uma situação de potencial hídrico total próximo de zero para valores negativos, os quais induzem o estresse hídrico, com a entrada em ação dos mecanismos fisiológicos de controle da transpiração. $\mathrm{O}$ principal mecanismo dessa natureza é o fechamento dos estômatos, que reduz simultaneamente a saída de vapor d'agua e a taxa de fotossíntese (Urban, 1991). Fenômeno semelhante ocorre com a nutrição mineral, pois somente uma pequena fração dos nutrientes fica retida pelo substrato, induzindo uma forte lixiviação pela drenagem. Em substratos desse tipo a fertirrigação contínua com uma solução nutritiva completa é quase obrigatória (Baille, 1994).

Os resultados apresentados são importantes para a produção comercial do tomateiro, pois mostram que substratos de baixo custo como a casca de arroz e o húmus proveniente da minhocultura se constituem em materiais apropriados para uso como substrato, possuindo características similares ao substrato comercial testado. A casca de arroz é um subproduto abundante da agroindústria arrozeira e o húmus pode ser produzido facilmente nas propriedades rurais. Indicam também que outras misturas de materiais podem ser empregadas com sucesso, desde que apresentem características físicas semelhantes àquelas mostrados neste trabalho. Entretanto, os substratos orgânicos são materiais biologicamente ativos que sofrem transformações no decorrer do tempo. Por isso, suas características físicas devem ser reavaliadas periodicamente e nenhuma generalização pode ser feita em relação a sua vida útil.

\section{AGRADECIMENTOS}

Os autores agradecem ao Eng. ${ }^{\circ}$ Agr ${ }^{\circ}$. Nereu Streck pelo fornecimento do húmus empregado nos ensaios e também à FAPERGS - Fundação de
Âmparo à Pesquisa do Estado do Rio Grande do Sul, pela concessão de uma bolsa de Iniciação Científica a um dos autores do trabalho.

\section{LITERATURA CITADA}

ALARCON, A.L.; MADRID, R.; EGEA, C.; RINCÓN, L. Respuesta del melón Galia ( $\mathrm{Cv}$. Revigal) sobre lana de roca, a diferentes aguas de riego y zonas de cultivo. Acta Horticulturae, v. 16 , p. $91-97,1997$.

ANDRIOLO, J.L.; POERSCKE, P.L. Cultivo do tomateiro em substratos. Santa Maria: UFSM - Centro de Ciências Rurais, 1997. 12 p. (Informe Técnico, 2).

ANDRIOLO, J.L.; DUARTE, T.S.; LUDKE, L; SKREBSKY, E.C. Crescimento e desenvolvimento do tomateiro cultivado em substrato com fertirrigação. Horticultura Brasileira, Brasília, v. 15, n. 1, p. 28 - 32, maio 1997.

BAILLE, M. Gestion global del cultivo fuera del suelo. In: JORNADA DE SUBSTRATOS, 2. 1994. Madrid: Sociedad Española de Ciencias Horticolas, 1994, 63 p.

BLANC, D. Les substrats. In : BLANC, M. ed Les cultures hors sol, Paris: INRA, 1987. p. 9 - 13 .

FAO. Protected cultivation in the mediterranean climate. Rome: Food and Agriculture Organization of the United Nations, 1990a. 313 p. (FAO Plant Production and Protection Paper, 90).

FAO. Soilless culture for horticultural crop production. Rome: Food and Agriculture Organization of the United Nations, 1990b. 188 p. (FAO Plant Production and Protection Paper, 101).

GRAS, R Proprietés physiques des substrats. In : BLANC, M. ed. Les cultures hors sol, Paris: INRA, 1987. p. 80 - 126.

MOINEREAU, J.; HERRMANN, P, FAVROT, J. C.; RIVIÈRE, L. M. Les substrats Inventaire, caractéristiques, ressources. In: BLANC, D. ed. Les cultures hors sol. Paris: INRA, 1987. p. 15 - 77.

MUSARD, M.; LETARD, M. Le maraîchage sous serres et abris en culture sur substrats. In : RASTOIN, F. ed. Cultures légumières sur substrat. Infos-Ctfil hors série, 1990. p. 5 - 7.

ROSA, A.; SOUSA, J.; CAÇO, J. Melancia em substrato de lã de rocha. Acta Horticulturae, v. 16, p. $127-131,1997$.

SALSAC, L.; CHAILLOU, S.; MOROTGAUDRY, J.; LESAINT, C.; JOLIVET E. Nitrate and ammonium nutrition in plants. Plant Physiology and Biochemistry, v. 25, n. 6, p. 805 - 812, 1997.

URBAN, L. Etat hydrique et production sous serre en hors sol. PHM Revue Horticole, v. 319, p. $37-43,1991$. 